\title{
The situation of anthrax which is on the territory of Ukraine
}

\author{
V.A. Sinitsyn ${ }^{1}$, U.M. Yanenko ${ }^{1}$, G.A. Zaviryukha ${ }^{1}$, T.B. Vasileva ${ }^{1}$, O.A. Tarasov $^{2}$, N.I. \\ Kosyanchuk $^{3}$, L.M. Muzykina² \\ ${ }^{1}$ State Centre of Innovation Biotechnologies, Kyev, Ukraine \\ ${ }^{2}$ Institute of Veterinary Medicine, The National Academy of Agrarian Sciences of Ukraine, Kyev, Ukraine \\ ${ }^{3}$ National University of Life and Environmental Sciences of Ukraine, Kyiv, Ukraine \\ E-mail: ulyanakuzyk@ukr.net
}

Received: 28.08.2019. Accepted: 28.09.2019

The article presents the anthrax monitoring studies for the period of 1920-2019 years. The statistical analysis on data regarding anthrax outbreaks among all regions of Ukraine, hot spots and the number of the old anthrax burial grounds with documentary evidence. During the investigated period it was counted 24955 anthrax outbreaks among different species of animals. The epizootic situation for anthrax in Ukraine nowdays has to be complex due to almost 10 thousand of the known old burial grounds and up to 6 thousand supposedly presented ones with unknown location. The total vaccination of cattle population significantly reduced the anthrax incidence, but the treat of new outbreaks cannot be completely eliminated, the potential danger of new outbreaks exists, moreover, in completely new forms of manifestation, including the arising risk of bioterroristic acts in recent years. The results of our research indicated that the occurrence of anthrax connected to the spreading and preserving of the pathogen in the soil and non sufficient vaccination program or presence of nonimmune cattle in the population. It should be noted that despite of the constant presence of the pathogen in the environment, anthrax pathogen usually does not acquire the manifestation of the large outbreak, even in areas where there were no preventive vaccinations of cattle. Thus, the problem of anthrax is still far from being resolved. Nowdays and in the near future B. anthracis having potential for actively spreading in the abiotic sphere, represents a potential danger to wild and farm animals, as well as to the human population in almost all countries of the world. Up to date more than 10,000 hot spots have been revealed and registered in Ukraine and 6,000 anthrax outbreaks have been documentally proved. Laboratory studies have confirmed the main source of infection was anthrax-infected animals, among which $71 \%$ were cattle. The main approach for the prevention and surveillance of anthrax is the compulsive immunization with live or inactivated vaccine and improving approaches for anthrax diagnostics. The presence of anthrax foci in the military conflict zone in the eastern regions of Ukraine, part of Donetsk and Lugansk oblast arise the issue of ensuring people's biosafety and lowering the risks of anthrax outbreaks. The part of territory involved in war conflict is out of Ukrainian officials surveillance, these regions can be considered as a high risk zone of possible anthrax outbreaks. In order to characterize ecology and epidemiology of anthrax, a historical anthrax database of all known anthrax outbreaks in Ukraine during 1993-2019 was developed. Human and animal cases are registered throughout the country, however the spatial distribution of cases is heterogeneous with clustering in some areas.

Case investigations show that a majority of the infections among humans were related to contact with cattle, while the second most frequent cause is contact with contaminated soil. Despite all investments and measures undertaken to control and prevent the disease, anthrax is still endemic to Ukraine with outbreaks. The main tool for the anthrax prevention and surveillance today is the applying of effective approaches for immunization and improving the diagnostic capacity for early detection and notification.

Keywords: Anthrax; spatio-temporial analisys; monitoring; biosafety

\section{Introduction}

For centuries anthrax has been a natural disaster, killing a huge amount of cattle and other ruminants and causing big economic losses. Case investigations show that a majority of the infections among humans were related to contact with cattle, while the second most frequent cause is contact with contaminated soil. (Doganay et al., 2015). The disease has a global distribution, but the incidence of livestock and people varies depending on the local ecology, the implementation of control strategies and socio-cultural practices that determine the spreading of infection from animals to people. (Hugh-Jones, 1999). The disease affects all mammal species including human often with lethal ending. Despite the fact that in developed countries, the situation with anthrax disease is sufficiently controlled, the disease continues to have devastating global consequences for poor groups of people who depend on small-scale livestock farming in rural areas (Sweeney et al., 2011, Molyneux et al., 2011). Today there is an idea of society that the anthrax disease has been eliminated long time ago. This contradicts the known data on the biological characteristics of the anthrax pathogen, indicating that the pathogen has survived in the soil for centuries. Once in the soil, under favourable conditions (the 
ambient temperature is not lower than $12^{\circ} \mathrm{C}$ ), the pathogen forms spores. In the spore form it can persist in the soil for an unlimited time, remaining viable and saving pathogenicity. Spores are resistant to extreme conditions, such as abrupt changes in $\mathrm{pH}$, thermal fluctuations, extreme cold and dry weather conditions, exposure to chemical agents, and so on. In certain environments, with the appearance of favorable conditions for the microorganism, they can remain viable for up to 200 years. Soil contaminated with anthrax spores remains a source of infection for sensitive animals or humans for a time longer than human lifetime (Hugh-Jones, 2002). Prolonged preservation of B. anthracis spores in the environment is a factor of impact the occurrence of regular outbreaks of the disease. Outbreaks can occur after a long period of time. For example, in Sweden, the disease occurred 27 years after the last outbreak (Lewerin et al., 2010). The main source of anthrax is a infected animal, which releases the pathogen into the environment with urine, feces, milk, and bloody secretions even before the clinical manifestation appear.

The scientific literature contains a huge array of information about the anthrax research. The history of the subject study, and especially the contribution of ukrainian scientists to the investigation of this disease and its surveillance, it is still not completely researched, and many of the well-known facts are quite contradictory.

The persistence of anthrax spores and their spread in many regions of the world create prerequisites for the occurrence of outbreaks, as well as sporadic and small group human cases (Bakulov et al., 1971, Bakulov, 2001). There is evidence that the long existence of foci of anthrax infection is provided by the saprophytic reproduction of bacilli in the soil and even in the water of open reservoirs (Bondaryov et al., 2001).

Anthrax is an acute infectious disease, characterized by severe intoxication of the body, fever, septicemia, the occurrence of edema and carbuncles, intestinal lesions, and sometimes lungs necritic lesions. Many species of domestic and wild animals, as well as humans, are affected. Anthrax of animals and humans continues to be a serious problem today in many countries of the world, regardless of their level of development.

According to the World Organisation for Animal Health (OIE) and the World Health Organization (WHO), over the past 15 years, more than 150,000 anthrax outbreaks have been registered in the world. Every year more than 2 million animals die, more than 40,000 people infected with anthrax pathogen (State Consumer Services Administration of Ukraine, 2019).

On the basis of GU "Ukrainian Research Anti-Plague Institute. I.I. Mechnikov Ministry of Health of Ukraine " annually hosts an event with the support of the US Department of State's Biosecurity Engagement Program (VER-DOS) and the US Civilian Research and Development Foundation (CRDF Global). The program is attended by representatives of the State Food Service, the Ministry of Health of Ukraine, the Ministry of Defence of Ukraine, the National Academy of Agrarian Sciences of Ukraine, research institutions. The subject of discussion at the meeting of specialists in the field of public health and veterinary medicine with international experts was to reveal the problematic issues and the implementation of an integrated approach to the surveillance on priority infectious diseases common to humans and animals, interdisciplinary interaction and determining the next steps and implementation of the "One Health" program. The purpose of its implementation is to promote more effective coordination and communication between the health, veterinary medicine, improvement of epidemiological surveillance, response and prevention of outbreaks of zoonotic diseases, including those that may have international significance.

Today, the issue of ensuring biosafety of people, defenders of the border of Ukraine, is particularly relevant because of the fighting in the territory of Donetsk and Lugansk regions. The territory is uncontrolled; this region can be considered a risk zone in the occurrence of the disease. To ensure a stable epizootic situation on anthrax, it is necessary to operate with data on the location of permanently unsuccessful locations, as well as the location of the cattle burial grounds. The purpose of our study is a retrospective analysis of the epizootic situation of anthrax in Ukraine from 1920-2019.

\section{Material and methods}

As the main source of data was used the catalogue of anthrax hot spots on the territory of Ukraine (former USSR) for 1920-1978 and 1978-2002 (edited by V. Ya. Shabliy). Also it was used the data obtained from the State Committee of Veterinary Medicine of Ukraine, as well as data from the State Research Institute for Laboratory Diagnostics and Veterinary-Sanitary Expertise on Anthrax Outbreaks in Ukraine 2000-2019 years.

\section{Results and Discussion}

The constant expansion of the scope of specific immunization of susceptible animals was a decisive reason for the decrease in the incidence of anthrax. In the former USSR over 270 million farm animals were vaccinated against anthrax every year. Mass vaccination of animals significantly reduced the incidence, but still did not fully eliminate the threat of new outbreaks of this infection, the potential risks of it made the hazard constant moreover in completely new perspectives, such as bioterrorism. 
It should be noted that at the beginning of the XXI century the spread of anthrax in Ukraine was not significant. In most cases, sporadic disease outbreaks in human caused by a gross violation of the current sanitary and veterinary legislation. The analysis of statistical data on registration of anthrax outbreaks of farm animals and monitoring of hot spots for this disease in Ukraine for the period of 1920-2018 was performed. It was identified 24,955 anthrax outbreaks in animals (Figure 1). Cases of anthrax outbreaks were recorded among all regions of Ukraine. The most of outbreaks was recorded within the period 1920-1970 (Hugh-Jones, 2002) then veterinary service of Ukraine started the registration of permanent anthrax foci and animal burial grounds. The study of these data shown that there was some peculiarities of the manifestation of infection. Among the whole amount of anthrax hot spots there was single outbreaks in 50,2 \% of cases, two or more outbreaks - in $49,8 \%$. Repeated outbreaks of the disease appear at different intervals, but the largest number of them $(68.0 \%)$ were recorded during the first five years after the first outbreak. Within 15 years after the first registration of the disease $98,7 \%$ of all repeated cases of anthrax were detected, and after a longer then 15 years period - only $6.3 \%$.

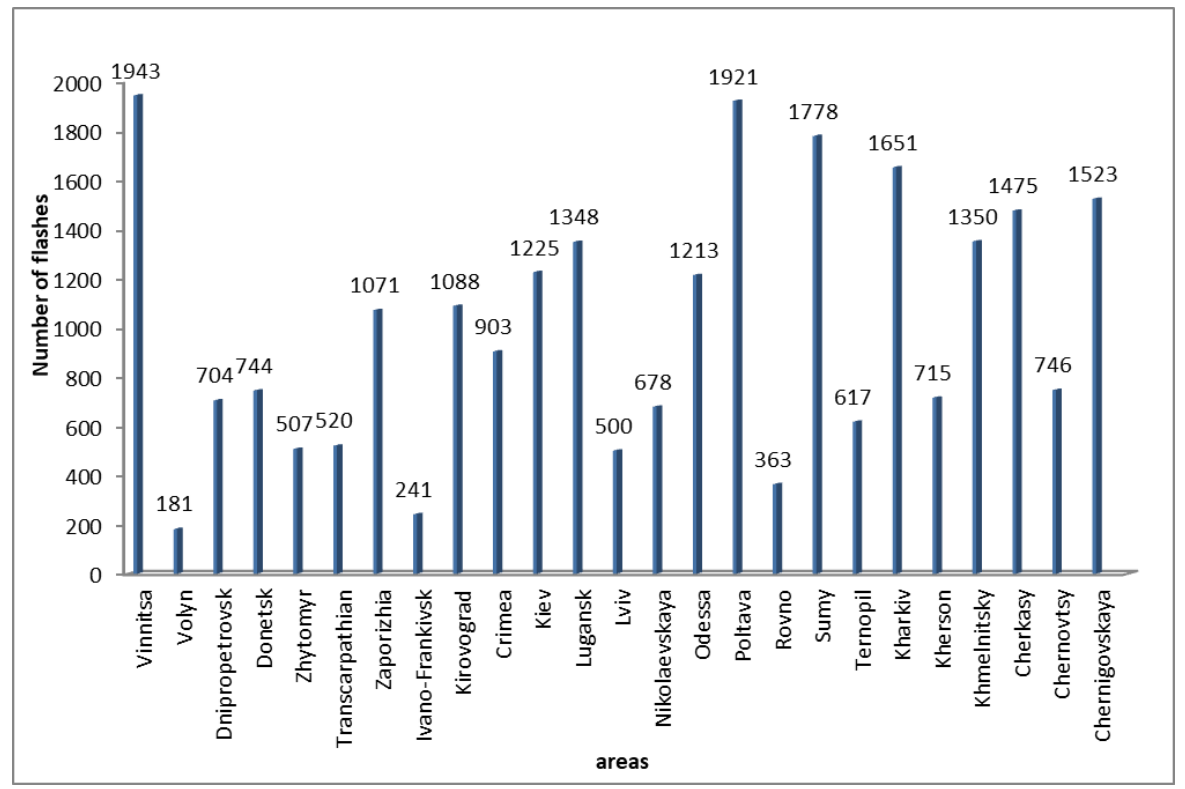

Figure 1. The dynamics of anthrax outbreaks from 1920 to 2018.

It should be noted that according to our research for 2013-2015 years no laboratory-confirmed anthrax outbreaks were detected among domestic animals. In March 2016 , on the territory of Chuguev, Kharkiv region B. anthracis was isolated from the pig carcass in the backyard farm was officially confirmed, the contaminated meat was used in food by 17 people and they got infected. In July 2017, in the Sumy region, the pathogen was isolated from two bodies of sheeps. The year 2018 also turned out to be unfavorable for anthrax. In october 2018, in the Odessa region, Saransk district, village Menylovka were hospitalized five people with anthrax signs and laboratory confirmed diagnosis. In this area, anthrax was last recorded in 2000 . So, for 99 years, the largest number of the anthrax cases was recorded in Vinnitsa (1943 cases) and Odessa (1922 cases) regions, while the smallest number of anthrax cases was recorded in Volyn (181 outbreaks) and Ivano-Frankivsk regions (241 outbreaks). Over the past 20 years, sporadic cases of the disease have been reported on the territory of 20 regions (oblast) of Ukraine (Figure 2). 


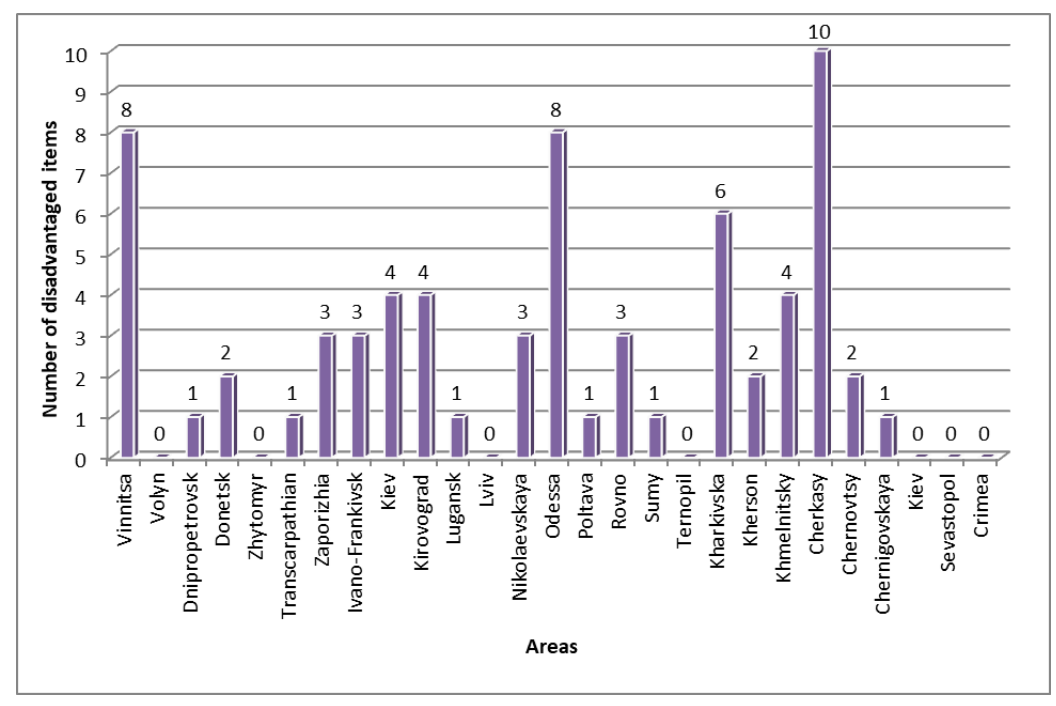

Figure 2. The number of unfavorable points for anthrax in the regions of Ukraine for 1999-2019. (According to the State Food Service of Ukraine).

The epizootic situation on anthrax in Ukraine is complex and tense. There are about 10 thousand unfavorable points and up to 6 thousand foci of the causative agent (Figure 3).

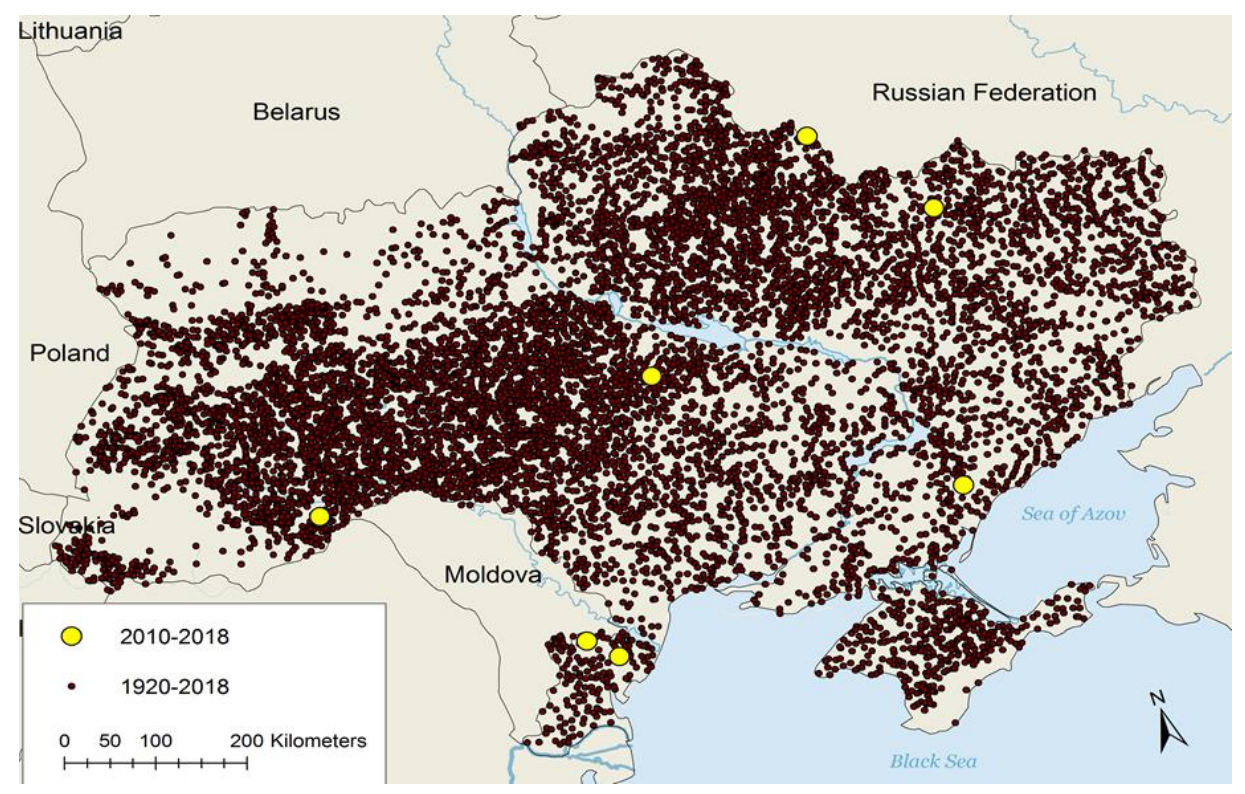

Figure 3. The number of disadvantaged items on anthrax for 99 years (image of GIS technology).

The most recent outbreaks in Ukraine suggest anthrax foci are still active, though the number of reported cases is low. While definitively diagnosed cases of anthrax disease are rare, these data do not comprehensively reflect 1) the total number of actual cases versus the number of reported cases or 2) the prevalence of the pathogen in the environment that can infect and be dispersed by wildlife species. While implementation of the vaccine has reduced agricultural anthrax transmission, border regions porous for un-vaccinated wildlife should be considered given that B. anthracis can infect and be dispersed by a large number of diverse ungulates species.

The greatest number of positive cases were reported in domestic cattle $-71,7 \%$; sheep and goats $-16,4 \%$; pigs $-7,8 \%$; horses $-4.1 \%$. Cases of animal disease have been reported in 24 regions (oblast) of 25 . Human cases of anthrax were reported in 15 regions of Ukraine of 25 (Figure 4). 


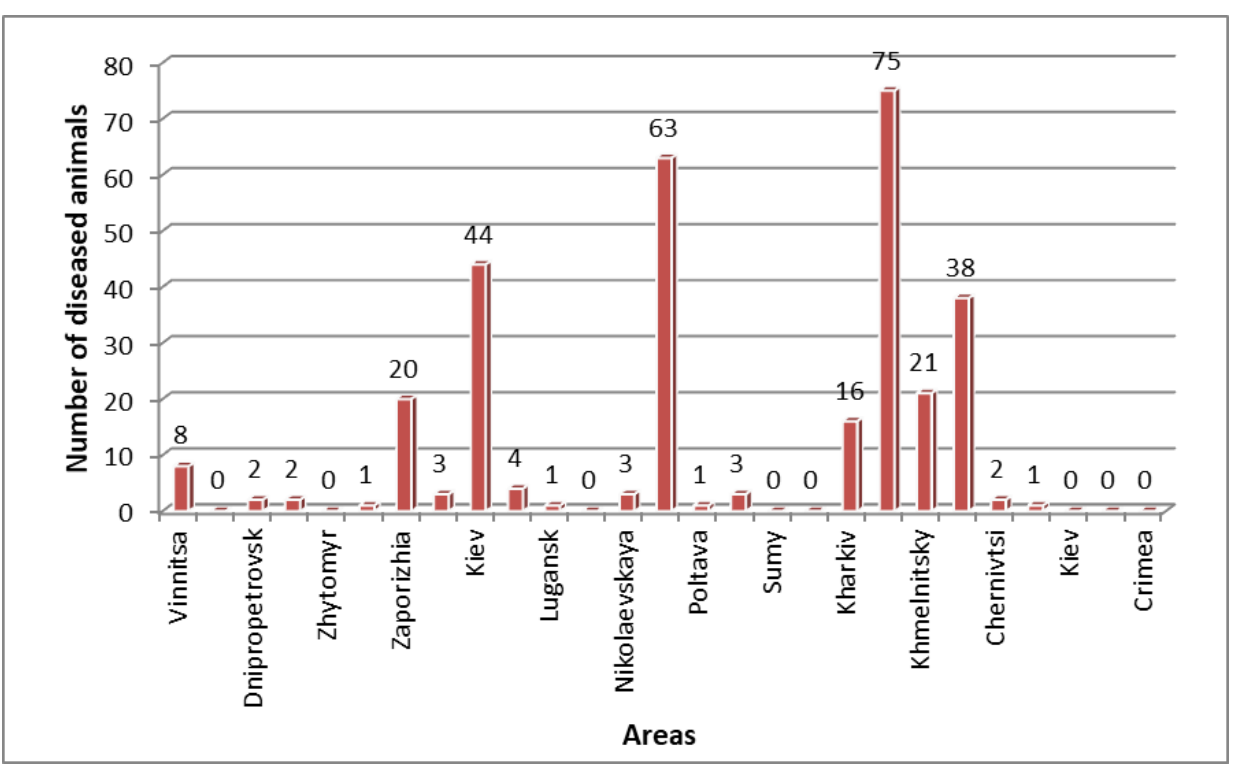

Figure 4. The number of animals with anthrax in Ukraine for 1999 -2019 (According to the State Food Service of Ukraine).

Despite the long history of active study of the disease and a huge number of scientific papers on the problem of anthrax, it continues to be in the center of attention of scientists and epidemiologists. This is due to the socio-economic consequences of the infection and to the insufficient study of various aspects of this biological phenomenon.

The results of our research indicate that the occurrence of anthrax connected to the spreading of the infectious agent in the soil and the gapes of animal vaccination program, espetially presence in the population non-immune animals. It should be noted that despite the constant presence of the pathogen in the environment, anthrax, as a rule, does not acquire the manifestation of an epidemic or large scale outbreaks, even in areas where were no preventive vaccinations of cattle.

Thus, the problem of anthrax and its causative agent is still far from being resolved. And now B. anthracis actively spreading in the abiotic sphere, representing a potential danger to wild and farm animals, as well as to the human population of almost all countries of the world.

Our special interest in the history of anthrax is also associated with one of the most important issues of modern epidemiology - the potential possibility of using B. anthracis as a biological weapon. The study of B. anthracis as a possible agent for the construction of biological weapons has a history of almost a century, and in modern conditions the realization of its potential is of great concern. Therefore, to ensure biosafety of the population, it makes sense to develop a strategy for monitoring, forecasting and organizing response measures with the threat of outbreaks (epidemics) of anthrax, and it is also necessary to improve the quality of laboratory diagnostics by introducing modern laboratory technologies for rapid detection (indication) and identification of pathogens.

The remaining issue is the immunization of people in risk areas. In Ukraine, there are no anthrax vaccine prophylaxis program in military units and veterinary units that introduce quarantine means in foci and hot spots. There are also present some gapes in vaccination of susceptible livestock. Comercially available vaccine preparations were used in general for cattle and small rumnants, while horse and pig populations remaining in the infection risk zone. So the challenge for finding the best option for prevention of anthrax in Ukraine remains open.

\section{Conclusions}

In Ukraine, anthrax is a zoonosis of concern for humans and animals nationwide. In order to characterize ecology and epidemiology of anthrax, a historical anthrax database of all known anthrax outbreaks in Ukraine during 1993-2019 was developed. Human and animal cases are registered throughout the country, however the spatial distribution of cases is heterogeneous with clustering in some areas. Case investigations show that a majority of the infections among humans were related to contact with cattle, while the second most frequent cause is contact with contaminated soil. Despite all investments and measures undertaken to control and prevent the disease, anthrax is still endemic to Ukraine with outbreaks. 
The main tool for the anthrax prevention and surveillance today is the applying of effective approaches for immunization and improving the diagnostic capacity for early detection and notification.

\section{References}

Bakulov, Y. A., Tarshys, M. G. (1971). Geografy `ya boleznej zhy `votnыx zarubezhnыx stran. M. Kolos, 200. (in Russian). Bakulov, Y. A., Gavrylov, V. A., Selyverstov, V.V. (2001). Anthrax, Vladymyr, 281. (in Russian).

Bondaryev, L. S., Zajcev, I. A, Tujnov V. O., Klysa M. M., Bondaryev L. S. (2001). Suchasni problemy sybirky. Infectious xvoroby, 4, 77-79. (in Ukrainian).

Derzhprodspozhy vsluzhba Ukrayiny (2019). Epizooty `chna sy tuaciya in the world: Information from the International Epizootic Bureau. (in Ukrainian).

Doganay, M., Demiraslan, H. (2015). Human anthrax as a re-emerging disease. Recent Pat Antiinfect Drug Discov, 10, 10-29. DOI: $10.2174 / 1574891 X 10666150408162354$.

Hugh-Jones, M. E., de Vos, V. (2002). Anthrax and wildlife. Rev. Sci. Tech., 21, 359-383.

Hugh-Jones, M. (1999). 1996-97 Global Anthrax report. J. Appl Microbiol. 87 (2), 189-191.

Lewerin, S.S., Elvander, M., Westermark, T., Hartzell, L.N., Norström, A.K., Ehrs, S., Knutsson, R., Englund, S., Andersson, A., Granberg, M., Bäckman, S., Wikström, P., Sandstedt, K. (2010). Anthrax outbreak in a Swedish beef cattle herd-1st case in 27 years: case report. Acta Vet. Scand., 52, 7. DOI:10.1186/1751-0147-52-7.

Molyneux, D., Hallaj, Z., Keusch, G.T., Mc Manus, D. P., Ngowi, H., Cleaveland, S., Kioy, D. (2011). Zoonoses and marginalised infectious diseases of poverty: where do we stand? Parasites Vectors, 4:106. DOI:10.1186/1756-3305-4106.

Sweeney, D. A, Hicks, C. W., Cui, X., Li, Y., Eichacker, P. Q. (2011). Anthrax infection. Am J Respir Crit Care Med, 184, 1333-1341. DOI:10.1164/rccm.201102-0209CI.

Citation: Sinitsyn, V.A., Yanenko, U.M., Zaviryukha, G.A., Vasileva, T.B., Tarasov, O.A., Kosyanchuk, N.I., Muzykina, L.M (2019). Monitoring Epizootic Situation on Anthrax in Ukraine 1920-2019. Ukrainian Journal of Ecology, 9(3), 113-118. 